OPEN ACCESS

Edited by:

Celina P. Leão,

University of Minho, Portugal

Reviewed by:

Mario Grande-de-Prado,

Universidad de León, Spain

Om Prakash Choudhary,

Central Agricultural University, India

${ }^{*}$ Correspondence:

Mohamed A. A. Mahdy

m_mahdi@vet.svu.edu.eg orcid.org/0000-0001-6402-2944

Specialty section:

This article was submitted to Educational Psychology, a section of the journal

Frontiers in Education

Received: 21 June 2021 Accepted: 17 November 2021 Published: 03 January 2022

Citation:

Mahdy MAA and Ewaida ZM (2022) Evaluation of the Emergency Remote Learning of Veterinary Anatomy During the COVID-19 Pandemic: Global Students' Perspectives. Front. Educ. 6:728365. doi: 10.3389/feduc.2021.728365

\section{Evaluation of the Emergency Remote Learning of Veterinary Anatomy During the COVID-19 Pandemic: Global Students' Perspectives}

\author{
Mohamed A. A. Mahdy ${ }^{1 *}$ and Zamzam M. Ewaida ${ }^{2}$ \\ ${ }^{1}$ Department of Anatomy and Embryology, Faculty of Veterinary Medicine, South Valley University, Qena, Egypt, ${ }^{2}$ Qena University \\ Hospital, South Valley University, Qena, Egypt
}

Purpose: The present study assessed the shift to remote teaching of veterinary anatomy during the COVID-19 pandemic based on students' perspectives.

Methods: Participants were invited to answer an anonymous online Google Form questionnaire using the snowball sampling method. Only students who studied anatomy online during the COVID-19 lockdown period were eligible to answer the questionnaire. A mixed-method research design was used to evaluate students' perspectives.

Results: A total of 961 participants were enrolled in this study from 87 countries and six continents. Data showed that the majority of students (81.6\%) were interested in studying anatomy online during the COVID-19 lockdown. Moreover, approximately 82\% of students were comfortable with the technological skills, and approximately $61 \%$ of students can understand online anatomy well during the lockdown. Furthermore, approximately $52.76 \%$ of students believed that online learning of anatomy suited for theoretical, $8.74 \%$ believed that it suited for practical parts, and $30.28 \%$ believed that it suited for both theoretical and practical parts. On the contrary, about $36.63 \%$ of students thought that online learning of anatomy could replace face-to-face teaching. In conclusion, shifting to remote teaching appears to be a good and convenient approach during the lockdown period as shown by students' interest to study anatomy online during the COVID-19 lockdown, their comfortability with the technological skills, and their level of understanding. However, practical classes with cadaver dissection and dealing with different anatomical specimens is essential for veterinary students; therefore, blended learning is recommended.

Conclusion: The study highlighted several challenges associated with studying anatomy online during the lockdown period and recommendation to overcome these challenges.

Keywords: evaluation, anatomy teaching, COVID-19, coronavirus, remote teaching, veterinary 


\section{INTRODUCTION}

The worldwide educational systems have been greatly affected by the COVID-19 pandemic, affecting a maximum number of about 1.5 billion learners (84.3\% of total enrolled learners) in 172 countries around the world as of April 1st, 2020, and then the number decreased afterward (UNESCO, 2020). Therefore, preventive measures have been applied in the educational sector to stop the spread of COVID-19, including either temporary closure or implemented localized closures of schools, colleges, and universities to protect staff and students' health. This is accompanied by shifting of face-to-face teaching to online and remote learning modes (Brassett et al., 2020; Singh et al., 2020; Wahab, 2020). Medical schools implemented e-learning regardless of their readiness (AlQhtani et al., 2021). The online teaching-learning during the pandemic period is considered a new experience for teachers, as well as students (Brassett et al., 2020; Mishra et al., 2020). Moreover, it tested the degree of readiness of the educational institutions worldwide (Singh et al., 2020). Therefore, universities that had a previous experience with educational technologies, such as videoconferencing platforms, were rapidly and successfully adapted (Aristovnik et al., 2020; Brassett et al., 2020; Pather et al., 2020; Wahab, 2020). On the contrary, many universities used online teaching for the first time after the emergence of the COVID-19 pandemic (Aristovnik et al., 2020; Cuschieri and CallejaAgius, 2020). Furthermore, at the beginning of the online education, several aspects were considered non-functional, such as platforms, communication, and interaction between students and professors, which negatively reflected on students' attitudes (Popa et al., 2020; Mahdy and Sayed, 2021).

Several studies have been carried out worldwide to investigate the influence of COVID-19 on the academic performance of university students (Aristovnik et al., 2020; Baticulon et al., 2020; Franchi, 2020; Kapasia et al., 2020; Mahdy, 2020; Marelli et al., 2020; Mishra et al., 2020; Mukhtar et al., 2020; Pather et al., 2020; Rashid et al., 2020; Romero-Blanco et al., 2020). These studies showed that it is crucial for students to adapt to the new situation during the COVID-19 pandemic (Baticulon et al., 2020; Pather et al., 2020). However, online learning is associated with several problems, such as availability, connectivity, cost and speed of internet, lack of electronic devices to access the online materials, and lack of effective communication between students and teachers (Brassett et al., 2020; Mahdy, 2020; Sahu, 2020; Mahdy and Sayed, 2021).

\section{Anatomy Teaching Before COVID-19}

Veterinary anatomy is considered as one of the basic science subjects of the veterinary curriculum. Anatomy education includes class teaching of theoretical parts, practical classes using dissected and prosected cadavers, plastinated specimens, plastic models (when possible), and modern imaging modalities, such as computed tomography and magnetic resonance imaging (Guevar and Rea, 2020). Practical anatomy is an essential part in veterinary students' education to understand the normal animal structure through cadaver dissection, which is considered the basic and most effective educational tool for learning and teaching the normal architecture of the body, and to develop surgical skills (Tiplady et al., 2011; Gutierrez et al., 2017; Mohamed, 2020). The traditional teaching of veterinary anatomy provides a direct contact (visual, tactile, and smell) with the anatomical specimens. It helps students to have handson practice and a real feeling of the size and texture of organs, allowing students to have a three-dimensional image of the anatomical structure (Guevar and Rea, 2020).

\section{Shift in Anatomy Teaching due to COVID-19}

COVID-19 provided an opportunity for anatomists to switch from conventional methods of teaching anatomy to produce online learning resources that offer flexibility for learners, as well as educators (Brassett et al., 2020; Byrnes et al., 2020). However, it is challenging to teach anatomy online via virtual classes and distance learning. This abrupt shift to the virtual mode needs extra efforts due to the lack of practical cadaver dissection, embryology models, bone specimens, microscopic slides, and face-to-face interaction with teachers. Moreover, it will have a great impact on students (Brassett et al., 2020; Franchi, 2020; Ross et al., 2020; Singh et al., 2020; Mahdy and Sayed, 2021). The current situation provides an opportunity for a careful assessment of the strengths and weaknesses of the online teaching of anatomy and compares it with conventional teaching methods (Brassett et al., 2020; Byrnes et al., 2020). It is crucial to assess the impact of shifting to online teaching of anatomy on students based on their concerns and views, student knowledge, and professional capabilities (Mahdy and Sayed, 2021). These studies will help the decision-makers to put plans to switch to online anatomy teaching, apply blended learning combining campus and online teaching together, and find a substitution for cadaveric specimens for the coming years (Brassett et al., 2020).

Recently, it has been reported that the COVID-19 lockdown negatively affected the academic performance of veterinary medical students and researchers (Mahdy, 2020). Mahdy and Sayed (Mahdy and Sayed, 2021) evaluated the online learning of veterinary anatomy during the lockdown period in an Egyptian veterinary medical school. Moreover, Longhurst et al. (Longhurst et al., 2020) analyzed the strength, weakness, opportunity, and threat (SWOT) of the adaptations to anatomical education in the United Kingdom and Republic of Ireland during the COVID-19 pandemic based on the perspectives of anatomical educators. The previous two studies highlighted several challenges, such as the lack of practical sessions, reduction of student engagement, and lack of technical support. Therefore, there is an essential need for academic collaboration, training on new technologies, inclusion of blended learning, free access to online resources, and development of alternative examination methods (Longhurst et al., 2020; Mahdy and Sayed, 2021). Cheng et al. (Cheng et al., 2020) conducted a national survey among anatomy educators to assess gross anatomy education in Chinese medical schools during the COVID-19 pandemic. The study revealed the low attitude of teachers toward the online teaching of anatomy because of the unique characteristics and requirements of anatomy education. Anatomy depends mainly on cadaver dissection, models, and specimens; therefore, virtual anatomy cannot replace hands-on experience to acquire 
knowledge (Cheng et al., 2020). The purpose of the current study was to evaluate the students' experiences and attitudes regarding the online shift of veterinary anatomy learning during the first lockdown. The objectives of the study were divided into quantitative and qualitative as follows:

\section{The Quantitative Research Objective}

-What are the veterinary students' attitudes toward the sudden shift of anatomy learning during the first lockdown?

-Are there any significant gender differences in students' attitudes to the change brought about by the COVID-19 pandemic during the first lockdown in relation to learning anatomy?

The qualitative research objective was to explore students' opinions about the emergency shift to online learning. The qualitative research questions were as follows:

-What are the main problems associated with the sudden shift of anatomy learning during the first lockdown?

-How the main problems could be improved?

\section{MATERIALS AND METHODS}

The current cross-sectional study assessed the students' satisfaction with the remote teaching of veterinary anatomy during the COVID-19 first lockdown using a survey questionnaire. The study used an integrative mixed-method design, combining components of both qualitative and quantitative research (Mahdy and Sayed, 2021).

\section{Participants}

The participants of this study comprised students who were studying veterinary anatomy online during the COVID-19 pandemic. Volunteer veterinary students who studied anatomy online during the pandemic were recruited through an announcement done via the "Veterinary Anatomy World" Facebook page (Facebook, Palo Alto, CA) operated by the author (https://www. facebook.com/VeterinaryAnatomyWorld) with about $32 \mathrm{~K}$ followers, mostly veterinary students. The aim of the study was clarified to the volunteer students, and then they were asked to share the questionnaire link among their colleagues in their schools through the class Facebook and WhatsApp groups. The study was done during the period from June 4 to December 20, 2020.

\section{Instrument}

An online Google Form (Google LLC, Mountain View, CA) questionnaire was modified from our previous study (shorturl.at/cuxHS) (Mahdy and Sayed, 2021). The full version of the questionnaire is available as Supplementary Material S1. The validity of the questionnaire was checked in an initial pilot study on 25 students, and their feedback was used to modify the questionnaire. Questionnaire reliability was 0.82 as indicated by Cronbach's alpha test.

\section{Questionnaire Design}

The Institutional Ethics Committee of the Faculty of Veterinary Medicine, South Valley University, Egypt, approved the study with approval number $(3 \mathrm{a} / 2020)$. Information about the aim of the questionnaire, voluntary participation, anonymity of participants, and data usage for research purposes was stated clearly at the beginning of the questionnaire. Participants were asked to provide their agreement, as a participant consent form, to participate in the study. The mixed-method research design, combining components of both qualitative and quantitative research, was used to evaluate students' perspectives. The questionnaire consisted of 20 questions. It was divided into two sections. The first section covered the students' demographic details, such as sex, age, country, university, and grade. It included four closed-ended and two open-ended questions. The second section evaluated the students' perception regarding the online learning of anatomy during the COVID-19 pandemic, such as their interest in studying anatomy online, satisfaction with online learning, device used to access the online materials, type of the provided studying materials, comfortability with technological skills, degree of understanding, the learning tools used, the average studying hours before and during the lockdown period, the possibility of replacing face-to-face teaching, and the most common problem detected during the online learning of anatomy. It included 13 closed-ended and one open-ended questions. Students were asked to write their thoughts about the shift to remote teaching of anatomy as a free text answer at the end of the questionnaire. To measure the individual opinion of students (i.e., interest, comfortability, satisfaction, agreement, or understanding), a 4-point Likert scale that ranged from strongly disagree $=1$ to strongly agree $=4$ was used (Mulyanti et al., 2020).

\section{Data Analysis}

The minimum number of participants (sample size) was calculated to be 384 participants (Dean et al., 2020). Data collection was done using a spreadsheet linked to the online Google Form questionnaire. The data were exported to the Microsoft Excel sheet (Microsoft Excel, Microsoft Corporation, Redmond, WA).

The data were analyzed using SPSS version 21.0 (IBM Corporation, Armonk. NY). The Shapiro-Wilk test was used to assess the normal distribution of data. Descriptive statistics were analyzed, and the percentage, frequencies, mean $(\mathrm{M})$, and standard deviation (SD) of each scale were calculated. The ordinal data obtained from the student responses were converted to numeric values as follows: strongly agree $=4$ points, agree $=3$ points, disagree $=2$ points, strongly disagree $=1$ point (Mayer and Cavallaro, 2019), and the mean \pm SD was calculated. An independent $t$-test was used to compare the differences between the scores for male and female students, and the effect size (Cohen's d) was calculated. The statistical difference was indicated when $p<0.05$. Open-ended questions were analyzed qualitatively using thematic analysis. 
TABLE 1 | Number of participants from different countries.

\begin{tabular}{|c|c|c|c|c|c|c|c|}
\hline Country & Number & Country & Number & Country & Number & Country & Number \\
\hline Philippines & 119 & Algeria & 8 & Canada & 3 & Togo & 2 \\
\hline Australia & 75 & Senegal & 8 & Croatia & 3 & Tunisia & 2 \\
\hline Egypt & 74 & Indonesia & 7 & Guatemala & 3 & Bolivia & 1 \\
\hline Pakistan & 57 & South Africa & 7 & Ireland & 3 & Botswana & 1 \\
\hline India & 55 & Albania & 6 & Italy & 3 & Cameroon & 1 \\
\hline USA & 54 & Czech Republic & 6 & Mongolia & 3 & Costa Rica & 1 \\
\hline Romania & 38 & Denmark & 6 & New Zealand & 3 & Spain & 1 \\
\hline Nigeria & 36 & Iraq & 6 & Russia & 3 & Greece & 1 \\
\hline Mexico & 34 & Jordan & 6 & Slovakia & 3 & Japan & 1 \\
\hline Poland & 33 & Libya & 5 & Sri Lanka & 3 & Kosovo & 1 \\
\hline United Kingdom & 30 & Uganda & 5 & Sudan & 3 & Laos & 1 \\
\hline Zambia & 25 & Colombia & 5 & Netherlands & 3 & Lithuania & 1 \\
\hline Nepal & 18 & Ethiopia & 4 & Austria & 2 & Namibia & 1 \\
\hline Bangladesh & 17 & Ukraine & 4 & Burkina Faso & 2 & Nicaragua & 1 \\
\hline France & 17 & Bulgaria & 4 & Ecuador & 2 & Palestine & 1 \\
\hline Somalia & 15 & Germany & 4 & Hungary & 2 & Paraguay & 1 \\
\hline Morocco & 13 & Ghana & 4 & Latvia & 2 & Portugal & 1 \\
\hline Belgium & 12 & Malaysia & 4 & Peru & 2 & Rwanda & 1 \\
\hline Kenya & 12 & Afghanistan & 3 & Serbia & 2 & Sweden & 1 \\
\hline Myanmar & 11 & Argentina & 3 & Syria & 2 & Tanzania & 1 \\
\hline Thailand & 10 & Turkey & 3 & Taiwan & 2 & UAE & 1 \\
\hline Brazil & 9 & Viet Nam & 3 & Timor-Leste & 2 & - & - \\
\hline
\end{tabular}

TABLE 2 | Sociodemographic characteristics of participants.

\begin{tabular}{|c|c|c|c|c|}
\hline & & Number (\%) & Male, n (\%) & Female, n (\%) \\
\hline \multirow[t]{4}{*}{ Educational level } & 1st-year students & 414 (43.08) & $175(18.21)$ & $239(24.87)$ \\
\hline & 2nd-year students & 425 (44.22) & 195 (20.29) & 230 (23.93) \\
\hline & 3rd-year students & $122(12.70)$ & $54(5.62)$ & 68 (7.08) \\
\hline & Total number & $961(100)$ & $424(44.12)$ & 537 (55.88) \\
\hline \multirow[t]{5}{*}{ Age-group (years) } & $18-20$ & $450(46.83)$ & $173(18.00)$ & 277 (28.82) \\
\hline & $21-25$ & 410 (42.66) & $191(19.88)$ & 219 (22.79) \\
\hline & $26-30$ & 82 (8.53) & 45 (4.68) & 37 (3.85) \\
\hline & Above 30 & 19 (1.98) & 15 (1.56) & $4(0.42)$ \\
\hline & Total number & $961(100)$ & $424(44.12)$ & 537 (55.88) \\
\hline
\end{tabular}

\section{RESULTS}

\section{Sociodemographic Characteristics of Participants}

A total of 974 students participated in the present study. However, 13 students did not agree to be included in the study; therefore, they were excluded. The final number of participants was 961 coming from 87 countries and six continents, with about $94.67 \%$ of the participants agreeing to be included in the study (Table 1). The distribution of the participants across the continents was as follows: the majority of students were from Asia (34.96\%), followed by Africa (24.35\%), Europe (20.29\%), Australia (7.80\%), North America (6.45\%), South America (5.83\%), and Oceania (New Zeeland, $0.31 \%)$. Most of the participants were female (55.88\%). The mean age of participants was $22.00 \pm 3.42$ years (range from 18 to 36 years), with a majority of participants (89\%) falling in the age range of $18-25$ years. Approximately $87 \%$ of the students were first- and second-year students (Table 2). All participating students confirmed that they studied anatomy online during the lockdown period.

\section{Evaluation of Emergency Remote Learning of Veterinary Anatomy During the COVID-19 Pandemic}

To evaluate the online learning of anatomy during the lockdown, the students were asked to express their opinion using 4-point Likert scale questions.

Data showed that the mean students' interest rate in studying anatomy online during the lockdown was $3.12 \pm 0.88$, with a majority of students $(81.58 \%)$ being interested in studying anatomy online during the COVID-19 lockdown. The mean score of the male respondents was significantly higher than that of female respondents regarding the interest in studying anatomy online during the COVID-19 lockdown ( $p=0.000$, Cohen's $d=0.36$ ). In addition, the mean students' comfortability rate with the technological skills was $3.14 \pm 0.81$, with a majority 


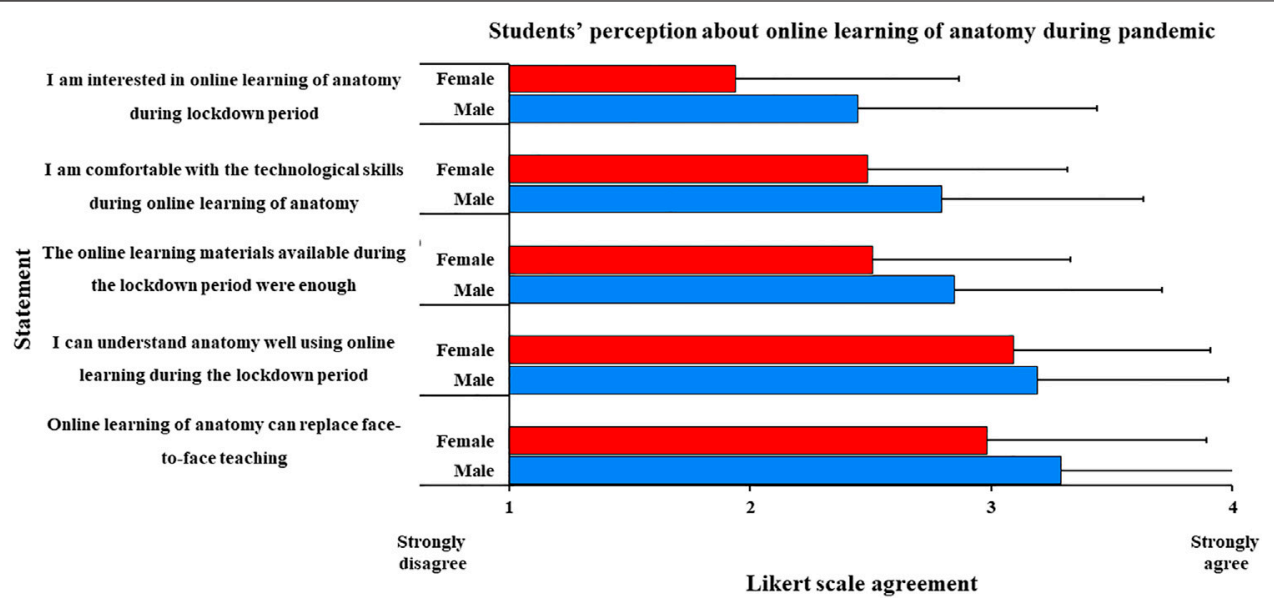

FIGURE 1 | A diagram showing students' perception about online learning of anatomy during the pandemic. Data were represented as mean \pm SD.

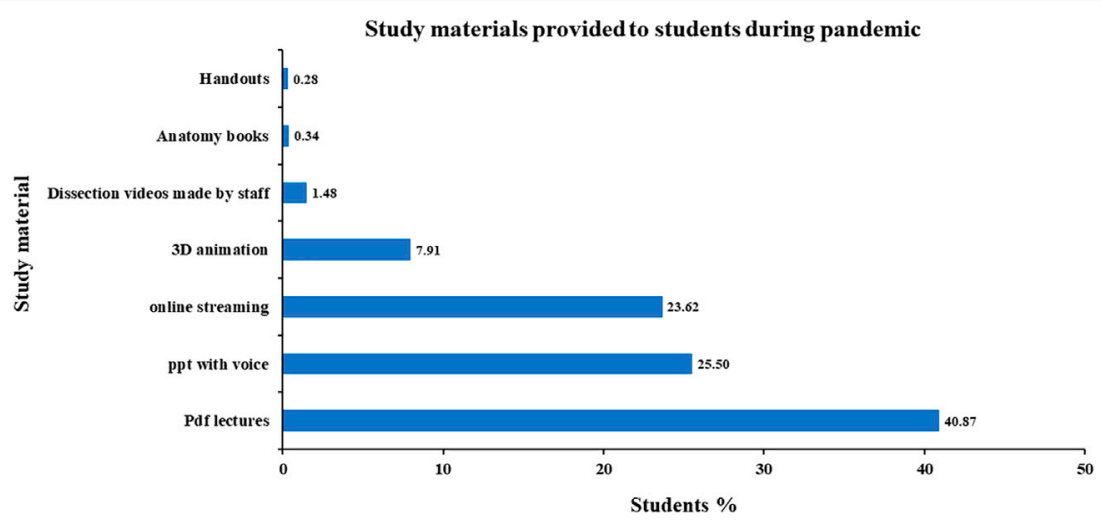

FIGURE 2 | A diagram showing the type of study material provided to students.

of students $(82.21 \%)$ being comfortable with the technological skills (using computer, surfing the Internet, downloading files, etc.) during online studying of anatomy during the lockdown. There was no statistically significant difference between the mean score of the male and female respondents regarding the comfortability with the technological skills $(p=0.057$, Cohen's $d=0.12$ ). Furthermore, the mean students' understanding rate of online learning of anatomy during the lockdown was $2.62 \pm 0.84$, with a majority of students $(60.46 \%)$ reporting that they were able to understand anatomy well using online learning during the lockdown. The mean score of the male respondents was significantly higher than that of female respondents regarding the understanding rate of online learning of anatomy during the lockdown ( $p=0.000$, Cohen's $d=0.36)$ (Figure 1).

The studying materials provided to students were mostly in the form of a Portable Document Format (pdf), followed by PowerPoint presentations with a recorded voice, online streaming using video-conferencing softwares (such as Moodle, Zoom, and blackboard), 3D animations, dissection videos made by staff members, anatomy books, and handouts
(Figure 2). The mean students' satisfaction rate with the provided studying materials was $2.66 \pm 0.86$. The mean score of the male respondents was significantly higher than that of female respondents regarding the satisfaction rate with the provided studying materials ( $p=0.000$, Cohen's $d=0.40$ ). However, about two-thirds of students $(60.46 \%)$ reported their satisfaction with the provided studying materials, with a majority of students (93.24\%) reporting their need for additional studying materials to help them understand the provided lessons of anatomy (Figure 1).

\section{The Tools Used for Online Learning of Anatomy}

To understand anatomy during the COVID-19 lockdown, students used several online tools. Of these tools, YouTube videos and anatomy textbooks were the most used tools. The other tools were as follows: educational websites, anatomy Facebook pages, educational applications, research articles, anatomy E. books, anatomy WhatsApp groups, and anatomy 


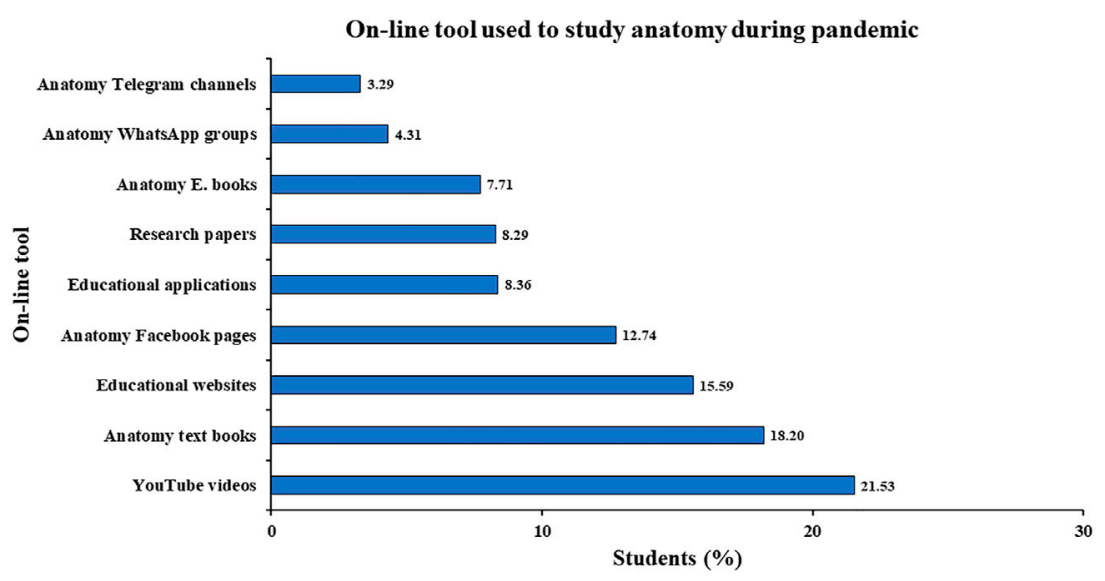

FIGURE 3 | A diagram showing the online tool used to study anatomy.

telegram channels (Figure 3). The electronic devices used to connect to the virtual system were as follows: smartphone $(42.07 \%)$ followed by a laptop (38.08\%), personal computer $(10.85 \%)$, and tablet $(9.00 \%)$.

\section{Students' Opinion Regarding Studying Anatomy Online During Lockdown}

The current results showed that approximately $52.76 \%$ of students believed that online learning of anatomy was most suitable for theoretical parts, about $8.74 \%$ of students believed that online learning of anatomy was most suitable for practical parts, and about $30.28 \%$ of students believed that online learning of anatomy was most suitable for both theoretical and practical parts. While $8.22 \%$ of students believe that online learning of anatomy was suitable for neither theoretical nor practical parts. On the contrary, about $36.63 \%$ of students thought that online learning of anatomy could replace face-to-face teaching (Figure 1). Here are quotations from students' opinion regarding studying anatomy online during lockdown:

\section{Students Who Support Online Learning of Anatomy}

Students who appreciated studying at home during the pandemic reported several reasons, such as flexibility, studying in a comfortable space at home, studying at convenient time, and saving travel time.

"E-learning is the best choice during pandemic, we should try to make it lively and interactive," "Online learning is a great tool to supplement our current curriculum due to the flexibility and wide array of sources it allows us, but it is difficult to replace being able to dissect and work with a cadaver," "I'm very happy and comfortable with online learning of anatomy during the pandemic," "It gives me more time to revise the lectures which makes me understood the content more," "I think it's a good approach to deliver online classes materials to the students because something is better than nothing," "I like e-learning better as you can go at your own pace and go back when needed," "e-learning is a good refresher or an extra to your normal studies, and vice-versa. E-learning can be a nice introduction to the anatomy class/training sessions," "I am actually finding learning of the theoretical concepts much easier as I can rewatch lectures and videos over and over to fully understand the concepts."

\section{Students Who Oppose Online Learning of Anatomy}

Students who opposed studying at home during the pandemic reported several reasons, such as difficulty of staying concentrated, less interactive, and lack of hands-on experience.

"It really isn't an ideal mode of teaching, but it is better than nothing during this time. I much prefer face to face teaching as I find it difficult to engage with online material," "It is actually a good method, but I don't prefer it because it is hard to focus and also interaction is still essential for further learning of the lesson," "It was really hard to orient myself inside the body and determine relationships of structures," "online learning in anatomy had not prepared me for real life situations and the practical version of the class should be reestablished," "I do not prefer anatomy e-learning courses because it is a practical subject, you need to experience learning it in person than just staring at the picture because there's really a difference in learning theoretically and experiencing it," "It is physically exhausting and mentally draining," "I just finished and get passed the subject of anatomy because I complied my requirements on my chosen subject. Unfortunately, I didn't fully learn," "nothing can replace the knowledge that you earn touching and dissecting specimens," "Trying to understand 3D things in 2D was very difficult," "It is difficult to be surgeons without dissecting a specimen or learning topography," "It is extremely hard to learn anatomy without physically being able to manipulate physical structures such as bones and muscles.”

\section{The Average Studying Hours of Anatomy Before and During Lockdown}

The average studying hours of anatomy decreased during the COVID-19 lockdown compared to the period before the lockdown. The percentage of students who spent $3-4,5-6$, 


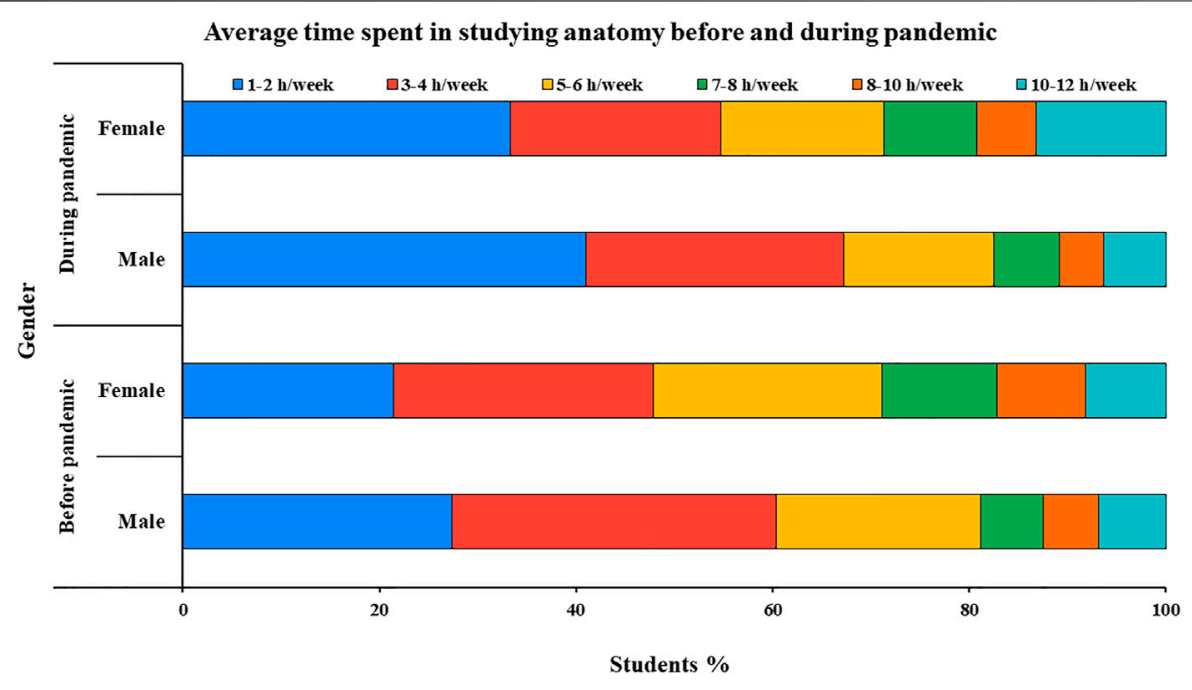

FIGURE 4 | Evaluation of average studying time of anatomy online before and during the lockdown period.

7-8, and 8-10 h/week studying anatomy during the COVID-19 lockdown decreased by $6.74,6.19,0.99$, and $2.32 \%$ compared to the period before the lockdown, respectively. Meanwhile, the percentage of students who spent 1-2 and 10-12 h/week studying anatomy during the COVID-19 lockdown increased by 13.26 and $2.98 \%$, respectively (Figure 4).

\section{The Problems Associated With Studying Anatomy Online During Lockdown}

Approximately 99 students answered the question regarding the problems associated with online learning of anatomy; these problems could be categorized in the following themes: lack of practical sessions (62), Internet-related issues (14), lack of interaction (13), delay of receiving feedback (4), training of lectures (3), and longer time to understand (3). Quotations from students' opinion regarding problems of studying anatomy online during the lockdown were also presented:

1) Lack of Practical Sessions

- "I think Is not enough with only theory I need practice to memorize good the concepts and structures," "I do not think it can be taught appropriately and comprehensively to students without cadavers"

2) Internet Connection-Related Issues

The Internet connection related had a negative effect on not only the emergency remote learning but also on the overall online learning experience. Students mentioned several difficulties related to Internet connection, such as poor or interrupted connection especially in rural areas and cost of Internet packages.

- "I can't understand the topic properly due to poor internet connection both from us and the professor"

- "It is hard to understand due to poor network"

- "I usually find it difficult in access high speed internet, hence I find myself missing classes due to technical problems"
- "It is hard to purchase bundles due to the pandemic"

3) Lack of Interaction Compared to Face-To-Face Teaching

- "I think anatomy is best learnt and understood by interaction with the lecturer because it is more practical than theoretical"

- "It is hard to interact with classmates, and learning becomes a very solo activity"

- "I lack motivation when I'm home all the time"

4) Waiting for Long Time to get Feedback From the Lecturer

- "I think online learning leave questions in the air"

- "Teachers have to reply on time to our questions"

5) The Necessity for Training Lecturers on the E. Learning Communication Skills

- "Lecturers should be well-trained on how to use technology", "teachers are also not certain about the e-learning"

6) The Need for Much Time to Understand Compared to Face-

To-Face Teaching

- "It takes more time to understand what the lecturer is teaching without the actual specimen"

- "I definitely have had to spend more time trying to orientate myself and understanding it,"

\section{Students' Suggestions to Improve the Online Teaching of Anatomy}

Approximately 55 students provided recommendations to improve online teaching of veterinary anatomy. These recommendations could be categorized in the following themes: improvement of teaching (35) and the enhancement of internet connection (20).

1) Improvement of Teaching: This theme includes three subthemes

A. Improvement of the provided study materials (27). 
- "Three-dimensional (3D) models, animations, and high-quality video presentations are required"

- "Using diagrams and good colored pic of the structures"

- "Diffuse lighting filters are needed during recording or live streaming to allow detail to be seen on camera"

- "Rehearse and record videos before online streaming to help bring questions before the session as these prevent bandwidth issues and losing detail"

B. Enhancement of teaching skills and teaching methods (7)

- "Training of lecturers on how to use online teaching applications"

- "Provide training on effective communication skills"

- "Provide questions after every lecture to test students' understanding"

- "Increase the interaction between students and lecturers".

- "The theoretical parts can stay online but weekly sessions using cadavers should be mandatory again"

- "It requires a more practical approach other than theory to fully grasp the concepts"

- "Online review, quizzes, videos, and other learning platforms to learn anatomy in our own houses would be a great help for us veterinary students"

C. Increase interaction between the lectures and students (1)

- "We should try to make it lively and interactive"

2) Improvement of internet services (20).

- "Provide a stable internet connection at cheaper rates for students during lockdown period"

- "Students should be provided with free internet packages during pandemic period".

- "Reliable internet connection should be available to all students,"

\section{DISCUSSION}

The present study explores the perception of veterinary medical students regarding the online learning of anatomy during the COVID-19 pandemic period. Recently, it has been reported that the COVID-19 pandemic has negatively influenced the academic performance of veterinary medical students and researchers (Mahdy, 2020). Moreover, our recent study highlighted several challenges that are encountered by students during online learning of veterinary anatomy during the lockdown period in Egypt (Mahdy and Sayed, 2021). However, there is no study evaluating the shift to remote teaching of anatomy during the COVID-19 pandemic worldwide; therefore, the present study provides an evaluation of the shift to remote teaching of veterinary anatomy during the COVID-19 pandemic based on students' perception. Secondarily, the study aimed to explore the problems associated with the shift to online learning, and aspects that can be improved.

The present data showed that a majority of students $(81.6 \%)$ were interested in studying anatomy online during the COVID19 lockdown, approximately $82 \%$ of students were comfortable with the technological skills, and approximately $61 \%$ of students were able to understand anatomy well using online learning.
These results partially agree with our recent results in Egyptian veterinary schools which showed that nearly $68 \%$ of students are interested in studying anatomy online during the lockdown, about $67 \%$ of students are comfortable with technological skills, and about $66 \%$ of students can understand anatomy well using the online learning mode (Mahdy and Sayed, 2021). The capacity of medical students to engage in online learning was affected by several factors, such as gender, age, academic level, annual income, Internet access, and the number of hours spent on online learning before the pandemic (Baticulon et al., 2020). In this regard, only $9 \%$ of medical and dental students were fully satisfied with studying anatomy via virtual classes, whereas $55 \%$ were moderately satisfied (Singal et al., 2020).

The studying materials provided to students were in the form of pdf, PowerPoint presentations with recorded voice, online streaming, and 3D animations. Online lectures are delivered through two main methods: synchronous and asynchronous teaching (Rashid et al., 2020). The synchronous teaching (done at real time using a virtual classroom) is the most dominant form to deliver online lectures (Aristovnik et al., 2020). This method offers more interaction between students and teachers; however, a high-speed and stable Internet connection is required (Mohmmed et al., 2020). In the asynchronous form of teaching, the lectures are available in several forms including PowerPoint presentations, pdf format, video recording, and audio recording (Aristovnik et al., 2020). These different forms are either sent to students or be available through university platforms (Aristovnik et al., 2020; Mahdy, 2020). Students prefer asynchronous mode of teaching than attending live lectures due to its flexibility and convenience with Internet-related issues (Cardall et al., 2008; Rashid et al., 2020).

Pre-recorded lectures are more preferable by students in studying anatomy due to several reasons: students can listen and understand without worry of taking notes, the possibility to repeat the parts that they did not understand well, the ability for each student to learn at his own pace, students can listen to the lecture at the convenient time to them, and the ability to pause and take notes when needed (Cuschieri and CallejaAgius, 2020; Mishra et al., 2020). However, the main disadvantages of the prerecorded lectures include lack of interaction between the lecturer and students, and absence of immediate response to students' queries (Cuschieri and CallejaAgius, 2020). On the other hand, posting only presentations is not recommended (Puljak et al., 2020).

To understand anatomy during the COVID-19 lockdown, students used several online tools, such as anatomy e-books, YouTube videos, educational websites, anatomy Facebook pages, educational applications, research papers, anatomy WhatsApp groups, and anatomy telegram channels. Students use several web-based platforms to find anatomical information, such as social media platforms, Internet search engines, and anatomy e-books (Barry et al., 2016). Social media has been reported as an educational tool for teaching anatomy, pathology, mathematics, and computing education to undergraduate students (Jaffar, 2012; Osaigbovo, 2018; Agbo et al., 2020; Mulenga and Marbàn, 2020; Mustafa et al., 2020). Using social media for 
educational purposes helps the students to share knowledge and information with their colleagues, enhance their academic performance, and to improve their skills in reading and writing (Palla and Sheikh, 2021). The availability and popularity of YouTube makes it an effective educational tool for studying medical anatomy (Jaffar, 2012; Barry et al., 2016; Mustafa et al., 2020). Social media platforms operated by anatomy teachers are considered as promising education tools through which trusted information is delivered; meanwhile, students can interact, inquire, and discuss with experts (Barry et al., 2016; Hennessy et al., 2020). WhatsApp and Facebook were the most favorite social media platform for learning of computing education in Nigeria. They help students' interaction and effective collaboration of students with their peers and teachers (Agbo et al., 2020). Integration of different social media platforms (Facebook, YouTube, and WhatsApp) in the teaching of mathematics to undergraduate students reflects a positive attitude of teachers in Zambia (Mulenga and Marbàn, 2020). In addition, students participating in Facebook groups with tutor assistance showed better understanding of the academic concepts and theories (Cuesta et al., 2016). On the other hand, it is important to design technological pedagogical content that meets the diverse needs of the university students (Hossain et al., 2020; Mahdy and Sayed, 2021).

The electronic devices used to connect to the virtual system were as follows: smartphone $(42.07 \%)$ followed by laptop (38.08\%), personal computer (10.85\%), and tablet $(9.00 \%)$. In agreement to the present results, Mahdy and Sayed (Mahdy and Sayed, 2021) reported that smartphone is the most commonly used electronic device used to access online materials of veterinary anatomy in Egyptian universities. It has been reported that medical students who use mobile devices in studying anatomy have a higher learning experience than others (Lazarus et al., 2017). Previous studies showed that smartphones are the most commonly used device by leaners followed by a laptop, desktop, and tablet (Baticulon et al., 2020; Hossain et al., 2020). In addition, the majority of students have more than one electronic device (Hossain et al., 2020). Unequal access to computers and Internet by students leads to the loss of effectiveness of the online learning ( $\mathrm{Xu}$ and $\mathrm{Xu}, 2019$ ).

Although nearly two-thirds of students showed their interest in studying anatomy online, and a majority of students believe that this type of learning was most suitable for either theoretical or practical parts or both, and less than half of students believed that online learning of anatomy could replace face-to-face teaching. Comparable results have been reported in Egyptian universities (Mahdy and Sayed, 2021). A recent study evaluated the shift to remote teaching of human anatomy in the University of Malta during the COVID-19 pandemic and showed that about half of students thought that remote teaching of anatomy is equivalent to face-to-face teaching (Cuschieri and CallejaAgius, 2020). Singal et al. (Singal et al., 2020) reported that medical and dental students are interested to study brain specimens in hand, while more than two-thirds of students feel difficulty in understanding embryology without models. The authors added that students missed several aspects of anatomy education, such as dissection lab, histology lab, face-to-face lectures, interaction with their mentors, and discussion with their classmates (Singal et al., 2020). A study done on undergraduate medical students in India revealed that about $31 \%$ of students prefer classroom learning only and $16 \%$ prefer online learning only, while $53 \%$ prefer combination of both methods (Shetty et al., 2020). Students' preference of classroom learning is due to student-teacher interaction, acquiring practical skills, and development of communication skills, while students' preference to online learning is due to its easy participation and time investment (Shetty et al., 2020). On the other hand, students showed significantly higher achievements with the blended learning mode than those engaged in the E-learning mode only (Al-Qahtani and Higgins, 2013). The blended learning mode enables students to express more learning in classroom discussion, personal interaction with tutors, and assignments than in E-Learning which depends only on online contents (Hameed et al., 2008). Furthermore, a combination of traditional teaching methods with E-learning methods improved the performance and learning outcomes of nursing students (Sheikhaboumasoudi et al., 2018). Therefore, it is recommended to apply blended learning after the pandemic to achieve the advantages of both online and traditional teaching.

Different learning styles have been reported: visual (learning mainly through seeing), auditory (learn mainly through hearing), read and write (learning mainly through read and write), and kinesthetic (learning mainly through touching, moving, and doing) learning styles (VARK) (Fleming and Baume, 2006; Hussain, 2017). Previous studies showed that a majority of the medical and veterinary students were multimodal (Lujan and DiCarlo, 2006; Neel and Grindem, 2010; Nuzhat et al., 2011; Kharb et al., 2013; Ojeh et al., 2017). On the other hand, the single preferred learning styles of medical students is visual style (Lujan and DiCarlo, 2006; Buşan, 2014), auditory style (Nuzhat et al., 2011; Peyman et al., 2014), read and write style (Ojeh et al., 2017), and kinesthetic style (Kharb et al., 2013). The current results showed that students recommended to add videos, pictures, and diagrams to the presentations because anatomy is more practical subject. Moreover, they recommended to provide audio recording with the text. It is recommended that educators should design their courses and teaching modes to meet the students' learning needs and preferred learning style (Ojeh et al., 2017).

Several challenges were faced by students in adapting to online learning of anatomy during the COVID-19 pandemic. Our results agree with the major challenges reported in other studies, such as the unstable network connection, lack of resources to join online learning, interrupted electricity connection, social isolation, eye strain, and lack of appropriate learning environment at home with the presence of more distractions that hinder their studies (Baticulon et al., 2020; Cuschieri and CallejaAgius, 2020; Mishra et al., 2020; Shetty et al., 2020; Choudhary, 2021; Mahdy and Sayed, 2021). In addition, the lack of motivation has been reported as a major problem with online learning due to the lack of immediate feedback from teachers (Mishra et al., 2020). Furthermore, spending long time daily in online classes using mobile phones induces overwhelming stress and several health issues (Sundarasen et al., 2020). These challenges affect the students' studying patterns, as well 
as well-being (Cuschieri and CallejaAgius, 2020). It has been reported that students need more time to comprehend online learning materials than ordinary learning methods (Baticulon et al., 2020). It is recommended that the university authorities should organize programs, rewards, or financial aids to help students to cope with mental and financial stressors due to the lockdown (Nurunnabi et al., 2020).

\section{Limitations of the Study}

This study has a number of limitations. This study focused to evaluate the students' experience with the online shift of veterinary anatomy learning during the COVID-19 pandemic; therefore, further research on different subjects of the veterinary curriculum could reveal different insights. The results of this study were based on the experience of university students, who might change their perceptions for a number of reasons. In addition, several countries were represented by a few numbers of participants as not all target students were reached. However, their inclusion in the study helped to get a global and diverse overview. Since the questionnaire invitation was distributed online, it is assumed that the students that are most active online are most likely to see and respond to the invitation to participate and, by association, the most likely to prefer online learning. The findings may therefore not represent all anatomy students but rather students with a higher online activity. Finally, the results of this study focused on differences between genders.

\section{CONCLUDING REMARKS}

The current study evaluated the students' perspectives regarding the shift to remote teaching of veterinary anatomy during the COVID-19 pandemic lockdown. Shifting to remote teaching appears to be a good and convenient approach during the lockdown period as shown by student interest to study anatomy online during the COVID-19 lockdown, their comfortability with the technological skills, and their level of understanding. However, practical classes with cadaver dissection and dealing with different anatomical specimens are essential for veterinary students. The study also highlighted several challenges

\section{REFERENCES}

Agbo, F. J., Olawumi, O., Oyelere, S., Awuni, D. E. K., Olaleye, S., Agjei, R. O., et al. (2020). Social media Usage for Computing Education : The Effect of the Strength and Group Communication on Perceived Learning Outcome. IJEDICT 16, 5-26.

Al-Qahtani, A. A. Y., and Higgins, S. E. (2013). Effects of Traditional, Blended and E-Learning on Students' Achievement in Higher Education. J. Comp. Assist. Learn. 29 (3), 220-234. doi:10.1111/j.1365-2729.2012.00490.x

AlQhtani, A., AlSwedan, N., Almulhim, A., Aladwan, R., Alessa, Y., AlQhtani, K., et al. (2021). Online versus Classroom Teaching for Medical Students during COVID-19: Measuring Effectiveness and Satisfaction. BMC Med. Educ. 21 (1), 452. doi:10.1186/s12909-021-02888-1

Aristovnik, A., Keržič, D., Ravšelj, D., Tomaževič, N., and Umek, L. (2020). Impacts of the COVID-19 Pandemic on Life of Higher Education Students: A Global Perspective. Sustainability 12 (20), 8438. doi:10.3390/su12208438 associated with studying anatomy online during the lockdown period and recommendations to overcome these challenges. Future studies in each country are recommended for better evaluation. It is crucial for educational institutions to review the professional development of their teaching staff and reconsider the digital competencies.

\section{DATA AVAILABILITY STATEMENT}

The raw data supporting the conclusions of this article will be made available by the authors, without undue reservation.

\section{ETHICS STATEMENT}

The Institutional Ethics Committee of the Faculty of Veterinary Medicine, South Valley University, Egypt, approved the study with approval number $(3 \mathrm{a} / 2020)$. The patients/participants provided their written informed consent to participate in this study.

\section{AUTHOR CONTRIBUTIONS}

All authors listed have made a substantial, direct, and intellectual contribution to the work and approved it for publication.

\section{ACKNOWLEDGMENTS}

The author would like to acknowledge all participants for their time, effort, and contributions.

\section{SUPPLEMENTARY MATERIAL}

The Supplementary Material for this article can be found online at: https:/www.frontiersin.org/articles/10.3389/feduc.2021.728365/ full\#supplementary-material

Barry, D. S., Marzouk, F., Chulak-Oglu, K., Bennett, D., Tierney, P., and O’Keeffe, G. W. (2016). Anatomy Education for the YouTube Generation. Anat. Sci. Educ. 9 (1), 90-96. doi:10.1002/ase.1550

Baticulon, R. E., Alberto, N. R. I., Baron, M. B. C., Mabulay, R. E. C., Rizada, L. G. T., Sy, J. J., et al. (2020). Barriers to Online Learning in the Time of COVID-19: A National Survey of Medical Students in the Philippines. Med. Sci. Educator 31, 615-626. doi:10.1007/s40670-021-01231-Z

Brassett, C., Cosker, T., Davies, D. C., Dockery, P., Gillingwater, T. H., Lee, T. C., et al. (2020). COVID-19 and Anatomy: Stimulus and Initial Response. J. Anat. 237 (3), 393-403. doi:10.1111/joa.13274

Buşan, A. M. (2014). Learning Styles of Medical Students - Implications in Education. Curr. Health Sci. J. 40 (2), 104-110. doi:10.12865/CHSJ.40.02.04

Byrnes, K. G., Kiely, P. A., Dunne, C. P., McDermott, K. W., and Coffey, J. C. (2020). Communication, Collaboration and Contagion: "Virtualisation" of Anatomy during COVID-19. Clin. Anat. 34, 82-89. doi:10.1002/ca.23649

Cardall, S., Krupat, E., and Ulrich, M. (2008). Live Lecture versus Video-Recorded Lecture: Are Students Voting with Their Feet? Acad. Med. 83 (12), 1174-1178. doi:10.1097/ACM.0b013e31818c6902 
Cheng, X., Chan, L. K., Pan, S.-Q., Hongmei, C., Li, Y.-Q., and Yang, X. (2020). Gross Anatomy Education in China during the Covid-19 Pandemic: A National Survey. Anat. Sci. Educ. 14, 8-18. doi:10.1002/ase.2036

Choudhary, O. P. (2021). Consequences of the COVID-19 Pandemic on Veterinary Anatomy Education in India. Int. J. Morphol. 39 (2), 623-624. doi:10.4067/ s0717-95022021000200623

Cuesta, M., Eklund, M., Rydin, I., and Witt, A.-K. (2016). Using Facebook as a Colearning Community in Higher Education. Learn. Media Tech. 41 (1), 55-72. doi:10.1080/17439884.2015.1064952

Cuschieri, S., and Calleja Agius, J. (2020). Spotlight on the Shift to Remote Anatomical Teaching during Covid-19 Pandemic: Perspectives and Experiences from the University of Malta. Anat. Sci. Educ. 13 (6), 671-679. doi:10.1002/ase. 2020

Dean, A., Sullivan, K., and Soe, M. (2020). OpenEpi: Open Source Epidemiologic Statistics for Public Health, Version. 20. Available at: www.OpenEpi.com (Accessed 10 11, 2020).

Fleming, N., and Baume, D. (2006). Learning Styles Again: VARKing up the Right Tree!. J. Educ. Dev. 7 (4), 4.

Franchi, T. (2020). The Impact of the Covid-19 Pandemic on Current Anatomy Education and Future Careers: A Student's Perspective. Anat. Sci. Educ. 13 (3), 312-315. doi:10.1002/ase.1966

Guevar, J. (2020). "The Evolution of Educational Technology in Veterinary Anatomy Education," in Biomedical Visualisation. Editor P. M. Rea (Cham: Springer International Publishing), 8, 13-25. doi:10.1007/978-3-030-47483-6_2

Gutierrez, J. C., Gomez Jaramillo, M., Sudel, G., and Prater, M. R. (2017). Anatomical Knowledge in Veterinary Medical Students in Chile. Investigación en Educación Médica 6 (22), 70-74. doi:10.1016/ j.riem.2016.04.004

Hameed, S., Badii, A., and Cullen, A. (2008). "Effective E-Learning Integration with Traditional Learning in a Blended Learning Environment," in European and mediterranean conference on information systems, Al Bustan Rotana Hotel, Dubai, May 25-26, 2008..

Hennessy, C. M., Royer, D. F., Meyer, A. J., and Smith, C. F. (2020). Social media Guidelines for Anatomists. Anat. Sci. Educ. 13 (4), 527-539. doi:10.1002/ ase. 1948

Hossain, S. F. A., Ying, Y., and Saha, S. K. (2020). “Systematic mobile Device Usage Behavior and Successful Implementation of TPACK Based on university Students Need," in Advances in Computer Vision.CVC. Editors K. Arai and S. Kapoor (Cham: Springer International Publishing), 1, 729-746. doi:10.1007/ 978-3-030-17795-9_55

Hussain, I. (2017). Pedagogical Implications of VARK Model of learning/Hussein. Int. J. Lit. Lang. Ling. 38, 33-37.

Jaffar, A. A. (2012). YouTube: An Emerging Tool in Anatomy Education. Anat. Sci. Educ. 5 (3), 158-164. doi:10.1002/ase.1268

Kapasia, N., Paul, P., Roy, A., Saha, J., Zaveri, A., Mallick, R., et al. (2020). Impact of Lockdown on Learning Status of Undergraduate and Postgraduate Students during COVID-19 Pandemic in West Bengal, India. Child. Youth Serv. Rev. 116, 105194. doi:10.1016/j.childyouth.2020.105194

Kharb, P., Samanta, P. P., Jindal, M., and Singh, V. (2013). The Learning Styles and the Preferred Teaching-Learning Strategies of First Year Medical Students. J. Clin. Diagn. Res. 7 (6), 1089-1092. doi:10.7860/JCDR/2013/5809.3090

Lazarus, L., Sookrajh, R., and Satyapal, K. S. (2017). Tablet Technology in Medical Education in South Africa: a Mixed Methods Study. BMJ Open 7 (7), e013871. doi:10.1136/bmjopen-2016-013871

Longhurst, G. J., Stone, D. M., Dulohery, K., Scully, D., Campbell, T., and Smith, C. F. (2020). Strength, Weakness, Opportunity, Threat (SWOT) Analysis of the Adaptations to Anatomical Education in the United Kingdom and Republic of Ireland in Response to the Covid-19 Pandemic. Anat. Sci. Educ. 13 (3), 301-311. doi:10.1002/ase.1967

Lujan, H. L., and DiCarlo, S. E. (2006). First-year Medical Students Prefer Multiple Learning Styles. Adv. Physiol. Educ. 30 (1), 13-16. doi:10.1152/ advan.00045.2005

Mahdy, M. A. A., and Sayed, R. K. A. (2021). Evaluation of the Online Learning of Veterinary Anatomy Education during the Covid -19 Pandemic Lockdown in Egypt: Students' Perceptions. Anat. Sci. Educ.. doi:10.1002/ase.2149

Mahdy, M. A. A. (2020). The Impact of COVID-19 Pandemic on the Academic Performance of Veterinary Medical Students. Front. Vet. Sci. 7, 594261. doi:10.3389/fvets.2020.594261
Marelli, S., Castelnuovo, A., Somma, A., Castronovo, V., Mombelli, S., Bottoni, D., et al. (2020). Impact of COVID-19 Lockdown on Sleep Quality in university Students and Administration Staff. J. Neurol. 268, 8-15. doi:10.1007/s00415020-10056-6

Mayer, J. D., and Cavallaro, R. (2019). Brief Mood Introspection Scale (BMIS): Technical and Scoring Manual. 3rd Edition. Durham, USA: UNH Personality lab, 29.

Mishra, L., Gupta, T., and Shree, A. (2020). Online Teaching-Learning in Higher Education during Lockdown Period of COVID-19 Pandemic. Int. J. Educ. Res. Open 1, 100012. doi:10.1016/j.ijedro.2020.100012

Mohamed, R. (2020). Attitude of Veterinary Students to Cadaveric Dissection in Teaching and Learning Veterinary Anatomy in the Caribbean. Ire 8 (1), 139. doi:10.5296/ire.v8i1.16761

Mohmmed, A. O., Khidhir, B. A., Nazeer, A., and Vijayan, V. J. (2020). Emergency Remote Teaching during Coronavirus Pandemic: the Current Trend and Future Directive at Middle East College Oman. Innov. Infrastruct. Solut. 5, 72. doi:10.1007/s41062-020-00326-7

Mukhtar, K., Javed, K., Arooj, M., and Sethi, A. (2020). Advantages, Limitations and Recommendations for Online Learning during COVID-19 Pandemic Era. Pak J. Med. Sci. 36, S27-S31. doi:10.12669/pjms.36.COVID19-S4.2785

Mulenga, E. M., and Marbàn, J. M. (2020). Social media Usage Among Pre-service Secondary Mathematics Teachers in Zambia. J. Res. Adv. Math. Educ. 5, 130-147. doi:10.23917/jramathedu.v5i2.9920

Mulyanti, B., Purnama, W., and Pawinanto, R. E. (2020). Distance Learning in Vocational High Schools during the Covid-19 Pandemic in West Java Province, Indonesia. Indonesian J. Sci. Technol. 5 (2), 271-282. doi:10.17509/ ijost.v5i2.24640

Mustafa, A. G., Taha, N. R., Alshboul, O. A., Alsalem, M., and Malki, M. I. (2020). Using YouTube to Learn Anatomy: Perspectives of Jordanian Medical Students. Biomed. Res. Int. 2020, 6861416. doi:10.1155/2020/6861416

Neel, J. A., and Grindem, C. B. (2010). Learning-style Profiles of 150 Veterinary Medical Students. J. Vet. Med. Educ. 37 (4), 347-352. doi:10.3138/jvme.37.4.347

Nurunnabi, M., Hossain, S. F. A. H., Chinna, K., Sundarasen, S., Khoshaim, H. B., Kamaludin, K., et al. (2020). Coping Strategies of Students for Anxiety during the COVID-19 Pandemic in China: a Cross-Sectional Study. F1000Res 9, 1115. doi:10.12688/f1000research.25557.1

Nuzhat, A., Salem, R. O., Quadri, M. S. A., and Al-Hamdan, N. (2011). Learning Style Preferences of Medical Students: a Single-institute Experience from Saudi Arabia. Int. J. Med. Edu. 2, 70-73. doi:10.5116/ijme.4e36.d31c

Ojeh, N., Sobers-Grannum, N., Gaur, U., Udupa, A., and Majumder, M. A. A. (2017). Learning Style Preferences: A Study of Pre-clinical Medical Students in Barbados. J. Adv. Med. Educ. Prof. 5 (4), 185-194.

Osaigbovo, I. (2018). Leveraging Social media for Pathology Education: Patterns and Perceptions Among Undergraduates. Ann. Trop. Pathol. 9 (2), 139-144. doi:10.4103/atp.atp_34_18

Palla, I. A., and Sheikh, A. (2021). Impact of Social media on the Academic Performance of College Students in Kashmir. Idd 49, 298-307. doi:10.1108/ IDD-06-2020-0061

Pather, N., Blyth, P., Chapman, J. A., Dayal, M. R., Flack, N. A. M. S., Fogg, Q. A., et al. (2020). Forced Disruption of Anatomy Education in Australia and New Zealand: An Acute Response to the Covid-19 Pandemic. Anat. Sci. Educ. 13 (3), 284-300. doi:10.1002/ase.1968

Peyman, H., Sadeghifar, J., Khajavikhan, J., Yasemi, M., Rasool, M., Yaghoubi, Y. M., et al. (2014). Using VARK Approach for Assessing Preferred Learning Styles of First Year Medical Sciences Students: A Survey from Iran. J. Clin. Diagn. Res. 8 (8), GC01-4. doi:10.7860/JCDR/2014/8089.4667

Popa, D., Repanovici, A., Lupu, D., Norel, M., and Coman, C. (2020). Using Mixed Methods to Understand Teaching and Learning in COVID 19 Times. Sustainability 12 (20), 8726. doi:10.3390/su12208726

Puljak, L., Čivljak, M., Haramina, A., Mališa, S., Čavić, D., Klinec, D., et al. (2020). Attitudes and Concerns of Undergraduate university Health Sciences Students in Croatia Regarding Complete Switch to E-Learning during COVID-19 Pandemic: a Survey. BMC Med. Educ. 20 (1), 416. doi:10.1186/s12909-02002343-7

Rashid, A. A., Rashid, M. R. A., Yaman, M. N., and Mohamad, I. (2020). Teaching Medicine Online during the COVID-19 Pandemic: A Malaysian Perspective. Bangladesh J. Med. Sci. 19, 77-81. doi:10.3329/bjms.v19i0.48170 
Romero-Blanco, C., Rodríguez-Almagro, J., Onieva-Zafra, M. D., Parra-Fernández, M. L., Prado-Laguna, M. D. C., and Hernández-Martínez, A. (2020). Sleep Pattern Changes in Nursing Students during the COVID-19 Lockdown. Ijerph 17 (14), 5222. doi:10.3390/ijerph17145222

Ross, C. F., Pescitelli, M. J., Smith, H. F., and Williams, J. M. (2020). Teaching Anatomy with Dissection in the Time of COVID-19 Is Essential and Possible. Clin. Anat. 34, 1135-1136. doi:10.1002/ca.23640

Sahu, P. (2020). Closure of Universities Due to Coronavirus Disease 2019 (COVID-19): Impact on Education and Mental Health of Students and Academic Staff. Cureus 12 (4), e7541. doi:10.7759/cureus.7541

Sheikhaboumasoudi, R., Bagheri, M., Hosseini, S. A., Ashouri, E., and Elahi, N. (2018). Improving Nursing Students' Learning Outcomes in Fundamentals of Nursing Course through Combination of Traditional and E-Learning Methods. Iran J. Nurs. Midwifery Res. 23 (3), 217-221. doi:10.4103/ijnmr.IJNMR_79_17

Shetty, S., Shilpa, C., Dey, D., and Kavya, S. (2020). Academic Crisis during COVID 19: Online Classes, a Panacea for Imminent Doctors. Indian J. Otolaryngol. Head Neck Surg., 1-15. doi:10.1007/s12070-020-02224-x

Singal, A., Bansal, A., Chaudhary, P., Singh, H., and Patra, A. (2020). Anatomy Education of Medical and Dental Students during COVID-19 Pandemic: a Reality Check. Surg. Radiol. Anat. 43, 515-521. doi:10.1007/s00276-02002615-3

Singh, K., Gaur, U., Hall, K., Mascoll, K., Cohall, D., and Majumder, M. (2020). Teaching Anatomy and Dissection in an Era of Social Distancing and Remote Learning. Adv. Hum. Biol. 10 (3), 90-94. doi:10.4103/aihb.aihb_87_20

Sundarasen, S., Chinna, K., Kamaludin, K., Nurunnabi, M., Baloch, G. M., Khoshaim, H. B., et al. (2020). Psychological Impact of COVID-19 and Lockdown Among university Students in Malaysia: Implications and Policy Recommendations. Int. J. Environ. Res. Public Health 17 (17), 6206. doi:10.3390/ijerph17176206
Tiplady, C., Lloyd, S., and Morton, J. (2011). Veterinary Science Student Preferences for the Source of Dog Cadavers Used in Anatomy Teaching. Altern. Lab. Anim. 39 (5), 461-469. doi:10.1177/026119291103900507

UNESCO (2020). Education: From Disruption to Recovery. Available at: https:// en.unesco.org/covid19/educationresponse (Accessed 10 25, 2020).

Wahab, A. (2020). Online and Remote Learning in Higher Education Institutes: A Necessity in Light of COVID-19 Pandemic. J. Higher Edu. 10 (3), 16-25. doi:10.5539/hes.v10n3p16

$\mathrm{Xu}, \mathrm{D}$., and $\mathrm{Xu}, \mathrm{Y}$. (2019). The Promises and Limits of Online Higher Education: Understanding How Distance Education Affects Access, Cost, and Quality. Washington, D.C.,USA: American Enterprise Institute, 1-40.

Conflict of Interest: The authors declare that the research was conducted in the absence of any commercial or financial relationships that could be construed as a potential conflict of interest.

Publisher's Note: All claims expressed in this article are solely those of the authors and do not necessarily represent those of their affiliated organizations, or those of the publisher, the editors, and the reviewers. Any product that may be evaluated in this article, or claim that may be made by its manufacturer, is not guaranteed or endorsed by the publisher.

Copyright (c) 2022 Mahdy and Ewaida. This is an open-access article distributed under the terms of the Creative Commons Attribution License (CC BY). The use, distribution or reproduction in other forums is permitted, provided the original author(s) and the copyright owner(s) are credited and that the original publication in this journal is cited, in accordance with accepted academic practice. No use, distribution or reproduction is permitted which does not comply with these terms. 